- Additional tables are published online only. To view these files, please visit the journal online (http://dx.doi.org/ 10.1136/gutjnl-2011-300111).

'Department of Medicine II, University of Munich, Munich, Germany

${ }^{2}$ Institute of Medical

Informatics, Biometry, and Epidemiology, University of Munich, Munich, Germany ${ }^{3}$ Institute of Clinical Radiology, University of Munich, Munich, Germany

${ }^{4}$ Bavarian Association of Compulsory Health Insurance Physicians, Munich, Germany

Correspondence to Dr Frank Thomas Kolligs, Department of Medicine II, University of Munich, Marchioninistr 15, 81377

Munich, Germany;

fkolligs@med.uni-muenchen.de

Revised 5 March 2012 Accepted 6 March 2012 Published Online First 23 April 2012

ORIGINAL ARTICLE

\title{
Risk factors for advanced neoplasia within subcentimetric polyps: implications for diagnostic imaging
}

\author{
Frank Thomas Kolligs, ${ }^{1}$ Alexander Crispin, ${ }^{2}$ Anno Graser, ${ }^{3}$ Axel Munte, ${ }^{4}$ \\ Ulrich Mansmann, ${ }^{2}$ Burkhard Göke ${ }^{1}$
}

\begin{abstract}
Objective Diagnostic imaging by CT colonography and capsule endoscopy is used to detect colonic lesions. Controversy exists regarding the work-up of subcentimetric lesions. The aim of this study was to identify risk indicators for advanced neoplasia (AN) in subcentimetric polyps.

Design Colonoscopies were classified on the basis of the largest lesion found. AN was defined as high-grade dysplasia, villous histology, or cancer. Logistic regression models were developed to identify risk factors for AN, and validated on separate datasets. A risk index based on the logistic regression was generated, and the number needed to screen (NNS) to detect AN was determined
\end{abstract}

Results 1077956 colonoscopies identified 106270 intermediate $(5-9 \mathrm{~mm})$ and 198954 diminutive ( $\leq 4 \mathrm{~mm}$ ) lesions; $13 \%$ of intermediate and $3.7 \%$ of diminutive lesions contained AN. The risk of AN was higher in intermediate than in diminutive lesions (OR 3.1; $95 \% \mathrm{Cl} 3.0$ to 3.3 ). Age $\geq 85$ versus $<45$ years was associated with ORs of 2.4 (95\% Cl 1.8 to 3.1) for intermediate polyps and $3.2(95 \% \mathrm{Cl} 2.3$ to 4.5$)$ for diminutive polyps. Pedunculated versus sessile morphology was associated with a higher risk of AN in intermediate (OR 2.0; 95\% Cl 1.9 to 2.2) and diminutive (OR 3.5; $95 \% \mathrm{Cl} 2.9$ to 4.1 ) lesions. In the combined analysis for subcentimetric lesions, ORs were 2.7 195\% Cl 2.2 to 3.3 ) for age $\geq 85$ versus $<45$ years, 1.1 (95\% $\mathrm{Cl} 1.1$ to 1.2$)$ for male sex, $1.6(95 \% \mathrm{Cl} 1.4$ to 1.7$)$ for occult blood, $1.3(95 \% \mathrm{Cl} 1.2$ to 1.5$)$ for overt blood in stool, $1.3(95 \% \mathrm{Cl} 1.2$ to 1.4$)$ for more than four lesions, and 2.2 (95\% Cl 2.1 to 2.3 ) for pedunculated versus sessile lesions. At median risk index values, the NNS was 9.3 (95\% Cl 9.1 to 9.5$)$ in individuals with intermediate lesions and $29.4(95 \% \mathrm{Cl} 28.5$ to 30.2$)$ in those with diminutive lesions. Compared with the NNS of 15 of the whole cohort, the majority of intermediate, but a minority of diminutive, lesions were deemed at high risk of AN.

Conclusion This study successfully identified risk factors and established a risk index for subcentimetric lesions. This has implications for the work-up of patients with subcentimetric lesions identified on diagnostic imaging.

\section{INTRODUCTION}

Colorectal cancer is among the most common causes of cancer-related morbidity and mortality. ${ }^{12}$ Screening for premalignant adenoma and cancer by

\section{Significance of this study}

What is already known on this subject?

- Diagnostic imaging by CT colonography and colon capsule endoscopy have been proposed as alternatives to optical colonoscopy for the detection of colonic neoplasia.

- There is no consensus about the post-test referral for polypectomy of patients with subcentimetric lesions.

- Risk factors for advanced neoplasia in subcentimetric lesions are not well understood, and therefore currently no stratification into low- and high-risk groups is possible.

What are the new findings?

- Age, sex, blood in stool, location, multiplicity and morphology of lesions are important risk indicators for advanced neoplasia in subcentimetric polyps.

- A risk index was developed that helps to identify low- and high-risk groups within the population of patients with subcentimetric lesions.

- The majority of people with intermediate, and a small subset with diminutive, lesions have risk indices associated with a number needed to screen stratifying them into the high-risk group, implicating immediate work-up by colonoscopy.

How might it impact on clinical practice in the foreseeable future?

- The assessment of risk factors for advanced neoplasia in patients with subcentimetric lesions may help in making evidence-based decisions about the work-up by colonoscopy in cases of subcentimetric findings identified on diagnostic imaging.

faecal occult blood tests (FOBT), sigmoidoscopy and colonoscopy reduces cancer incidence and cancer-specific death and is recommended by national guidelines. ${ }^{34}$ The American joint guideline also endorses new tests, including faecal DNA tests and virtual colonoscopy by $\mathrm{CT}^{3}$ In addition, colon capsule endoscopy (CCE), which has been shown to have a reasonably high sensitivity for colonic lesions, ${ }^{5} 6$ has recently been introduced as a diagnostic tool in several countries around the world 
Especially for individuals non-compliant to colonoscopy, for patients receiving anticoagulation therapy, older patients, and those with significant comorbidities, diagnostic imaging may be a valuable and less invasive approach than colonoscopy. However, CTC and CCE have in common that they can detect but not remove polyps. Therefore patients with polyps need to be referred for conventional colonoscopy.

The overall prevalence of polyps in average-risk, asymptomatic adults is at least $20-30 \%$. Still, only roughly one in three of these individuals have polyps $\geq 10 \mathrm{~mm} .^{7-11}$ All adenomas $\geq 10 \mathrm{~mm}$ in size are, per definition, advanced adenomas. ${ }^{12}$ Advanced neoplasia, the main target of colorectal screening and diagnosis, is defined as advanced adenoma or cancer. Subcentimetric adenomas of tubulovillous or villous architecture and those carrying high-grade dysplasia have also been recognised as advanced adenoma because they bear an increased risk of progression to colorectal cancer. However, only a fraction of subcentimetric lesions are advanced neoplasia; the majority of subcentimetric lesions consist of non-advanced adenoma, hyperplastic lesions and other benign histologies. ${ }^{13}$ While it is generally agreed on that patients with polyps $\geq 10 \mathrm{~mm}$ in diameter found on CTC should undergo polypectomy, ${ }^{14} 15$ a clinical dilemma exists about the work-up of those with subcentimetric lesions. ${ }^{16-18}$ The American College of Radiology has proposed re-examining people with single polyps of intermediate size found on screening CTC by another CTC examination 3 years later alternatively to immediate colonoscopy for polypectomy. ${ }^{15}$ Immediate colonoscopy is suggested only if three or more polyps $6-9 \mathrm{~mm}$ in size or polyps $\geq 10 \mathrm{~mm}$ are detected. The same proposal considers $6 \mathrm{~mm}$ as the minimum size for reporting polyp lesions. The European Society of Gastrointestinal and Abdominal Radiology recommends that polyps $\leq 4 \mathrm{~mm}$ found on CTC may be ignored. ${ }^{19}$ In contrast with these proposals, the American College of Gastroenterology recommends that patients with polyps $\geq 6 \mathrm{~mm}$ and those with three or more polyps of any size should be offered colonoscopy and polypectomy. ${ }^{18}$ Moreover, the American College of Gastroenterology recommends reporting of polyps of any size. Another important aspect in this context is that histology is required for the determination of surveillance intervals, which is commonly available after endoscopic removal of adenoma but not if a lesion identified by diagnostic imaging is not followed-up by endoscopy. ${ }^{4} 2021$ To solve the clinical dilemma and to ensure costeffectiveness of CTC and CCE, it is essential to establish algorithms indicating which subcentimetric findings need to be followed-up by colonoscopy, which can be safely controlled by repeat diagnostic imaging, and which can possibly be ignored.

A previous study attempting to identify risk factors within subcentimetric polyps was limited by a small sample size. ${ }^{13}$ To identify risk indicators for advanced neoplasia in subcentimetric lesions and to improve management of the respective patients, we performed an analysis of a large database of outpatient colonoscopies. We sought to analyse the frequency and relative distribution of polyps found according to size and histology and to identify risk indicators for advanced neoplasia within subcentimetric lesions. We intended to develop a risk index for individuals with diminutive and intermediate lesions.

\section{MATERIALS AND METHODS \\ Bavarian registry of outpatient colonoscopies}

In Bavaria, Germany, $83 \%$ of the population of 12.5 million inhabitants is insured by a public system, the compulsory health insurance (CHI). Starting at age 55, CHI insurants are entitled to two screening colonoscopies at an interval of 10 years. In addition, guaiac-based FOBT is offered annually from age 50 to 54 and biannually from age 55 to those refusing colonoscopy. Symptomatic insurants have free access to diagnostic colonoscopy independent of age. In 2006 the Bavarian Association of CHI Physicians (Kassenärztliche Vereingung Bayerns, KVB) introduced a central colonoscopy database. All outpatient colonoscopies performed in CHI patients are documented electronically via the internet in this database. Photographs of the caecal landmarks and complete online documentation are requirements for reimbursement. Reimbursement is higher in the case of polypectomy. Items documented in the database include age, sex, family risk, indication for colonoscopy (eg, screening, surveillance, diagnosis), symptoms (eg, blood in stool, FOBT positive, anaemia, diarrhoea, obstipation), sedation, complications, polyp count (one, two to four, or more than four polyps), localisation of lesions (sigma or rectum vs rest of colon vs lesions in both regions), and morphology, size and histology of the largest lesion found. The size of the largest polyps is documented according to three size groups, $\leq 4 \mathrm{~mm}$ (diminutive), 5-9 $\mathrm{mm}$ (intermediate) and $\geq 10 \mathrm{~mm}$ (large).

No individual patient identification data are contained in the database. Contents and the data collection procedure are regulated by federal guidelines (Krebsfrüherkennungs-Richtlinie), a contract between KVB and all health funds in Bavaria, which has been approved by the Bavarian governmental authority for data protection. For the present retrospective analysis, colonoscopies performed in people younger than 18 years and people with a history of chronic inflammatory bowel disease, as well as repeat examinations, were excluded from the analysis. In the case of repeat examinations, only the index colonoscopy was included. Biopsy specimens were evaluated by local pathologists. The findings on colonoscopy were categorised on the basis of the most advanced lesion found. Advanced adenoma was defined as an adenoma that had high-grade dysplasia, had villous or tubulovillous histological characteristics, or was $\geq 10 \mathrm{~mm}$ in diameter, or any combination thereof. Advanced neoplasia was defined as cancer or advanced adenoma.

\section{Statistical analysis}

Distributions of characteristics of patients, examinations, complications and detected lesions were described using absolute and relative frequencies. We modelled the risks of advanced adenoma, cancer and advanced neoplasia in patients with lesions using logistic regression models including the following set of independent variables: lesion count, size and histology of the largest lesion, localisation of lesions, gender, age, known family risk, and colonoscopy indication. We used the same fixed set of independent variables in all our models - that is, we did not use any variable selection algorithm based on $p$ values or goodnessof-fit criteria. To facilitate interpretation, we refrained from modelling interactions between the independent variables. Only lesions with known histology and size were included in the logistic regression models. Separate models were fit for different outcomes (advanced adenoma, advanced neoplasia, cancer) and lesion sizes (diminutive, intermediate, subcentimetric (ie, diminutive or intermediate), large). Number needed to screen (NNS) to detect one lesion fulfilling the respective outcome criteria was calculated as the inverse of the predicted outcome probability from the regression model. The NNS of the whole cohort was adopted as a guide to efficient post-test referral for polypectomy. For internal validation of our results, we followed Regula et al, ${ }^{10}$ dividing our sample into a randomly selected derivation set (two-thirds of the total sample) and a validation 
set (one-third). The risk index for advanced neoplasia is based on the model for subcentimetric lesions from the derivation set. Regression coefficients with a significant Wald test $(p<0.05)$ were multiplied by 10 and subsequently rounded to the nearest integer. The results on the predictive power of the index are based on the validation set. All analyses were performed using SAS V.9.2 for Linux.

\section{RESULTS}

A total of 1105092 colonoscopies were documented in the database between 2006 and 2009. After exclusion of 18274 colonoscopies performed in people with chronic inflammatory bowel disease, 5762 repeat examinations, and 3100 colonoscopies because of age <18 years, a total of 1077956 colonoscopies were included in the analysis. Of these, $258116(23.94 \%)$ colonoscopies were screening studies, 137923 (12.79\%) were performed for post-adenoma and 49153 (4.56\%) for post-cancer surveillance, 53039 (4.92\%) were work-ups on a positive FOBT, 104864 (9.73\%) for overt blood in stool, and $474861(44.05 \%)$ for other signs and symptoms (table 1). More women $(56.17 \%)$ had colonoscopy than men (43.83\%; 605515 vs 472441). Increased family risk was the reason for 66007 (6.12\%) colonoscopies. Intravenous sedation was used in 1012360 (93.92\%) colonoscopies. The caecum was reached in $97.61 \%$ cases. A total of $2219(0.2 \%)$ complications were documented.

Lesions were revealed by 401696 (37.27\%) colonoscopies: 198954 of these lesions were diminutive ( $\leq 4 \mathrm{~mm}$ ), 106270 were intermediate $(5-9 \mathrm{~mm})$, and 53490 were large $(\geq 10 \mathrm{~mm}$ ) (table 2). A total of 62991 patients had advanced adenoma; in 6522 $(10.35 \%)$ cases, these were diminutive, in 12751 (20.24\%) intermediate, and 43138 (68.48\%) large. Cancer was found in $8840(0.82 \%)$ patients; of these cancers, 858 (9.71\%) were diminutive, 1083 (12.25\%) were intermediate, and 2152

Table 1 Demographic characteristics and performance of colonoscopy

\begin{tabular}{lc}
\hline Characteristic & $\mathbf{n}(\%)$ \\
\hline Total & $1077956(100.00)$ \\
Age group (years) & \\
$\quad$ Younger than 45 & $181133(16.80)$ \\
$45-54$ & $179941(16.69)$ \\
$55-64$ & $298323(27.67)$ \\
$65-74$ & $303820(28.18)$ \\
$75-84$ & $105218(9.76)$ \\
84 and older & $9521(0.88)$ \\
Sex & \\
Female & $605515(56.17)$ \\
Male & $472441(43.83)$ \\
Increased family risk & $66007(6.12)$ \\
Indication for colonoscopy & \\
Screening & $258116(23.94)$ \\
FOBT+ & $53039(4.92)$ \\
Post-adenoma surveillance & $137923(12.79)$ \\
Post-cancer surveillance & $49153(4.56)$ \\
Overt blood in stool & $104864(9.73)$ \\
Other signs and symptoms & $474861(44.05)$ \\
Performance of colonoscopy & \\
Intravenous sedation & $1012360(93.92)$ \\
Caecal intubation & $1052139(97.61)$ \\
Complications & \\
$\quad$ Bleeding & $1662(0.15)$ \\
Perforation & $235(0.02)$ \\
$\quad$ Cardiorespiratory & $322(0.03)$ \\
\hline
\end{tabular}

FOBT, faecal occult blood test.
(24.34\%) were large. The size of 4747 (53.70) cancers was not known. In total, 71831 (6.66\%) advanced neoplasias were detected: 7380 (10.27\%) were diminutive, 13834 (19.26\%) were intermediate, and 45290 (63.05\%) were large. The Prevalence of high-grade dysplasia, villous or tubulovillous histology, and cancer within lesions according to size and variable analysed is given in table 3 .

The results of the logistic regression analyses for patients with subcentimetric lesions in the derivation and the validation sample are shown in table 4 . The modelling revealed the following risk indicators of advanced neoplasia in subcentimetric lesions: age, male sex, the simultaneous presence of proximal and distal lesions, occult or overt blood in stool, multiplicity of polyps, and flat or pedunculated morphology of polyps. The OR of intermediate compared with diminutive lesions to carry advanced neoplasia was 3.11 (95\% CI 2.98 to 3.25 ; $\mathrm{p}<0.001$ ). The strongest risk indicators in intermediate and diminutive lesions were age and morphology of the largest lesion found. Compared with adults $<45$ years of age, people $\geq 85$ years with an intermediate or diminutive lesion revealed ORs of 2.39 (1.84 to 3.10; $\mathrm{p}<0.001$ ) and 3.21 (2.31 to 4.48; $\mathrm{p}<0.001$ ), respectively. Compared with people with sessile lesions, those carrying a pedunculated intermediate polyp had an OR of 2.03 (1.91 to $2.15 ; \mathrm{p}<0.001)$ in the case of an intermediate lesion and an $\mathrm{OR}$ of 3.46 (2.90 to 4.13; $\mathrm{p}<0.001)$ in the case of a diminutive lesion. The ORs for the whole dataset and a risk factor analysis for the categories villous/tubulovillous adenoma, high-grade dysplasia, and cancer are presented in online supplementary table 1 .

Table 5 details the calculation of the risk index based on the identified risk indicators age, sex, family risk, presence of overt or occult blood in stool, and the polyp-associated factors morphology, size, and location. The NNS to find a diminutive or intermediate lesion carrying advanced neoplasia for the individual index values can be derived from figure 1. A risk index of 10 indicates an NNS of 9.3 (95\% CI 9.1 to 9.5) in the case of an intermediate lesion, and an NNS of 26.6 (95\% CI 25.9 to 27.3 ) in the case of a diminutive lesion. An NNS $<10$ is not reached below a risk index of 21 in the diminutive category. Figure 1 shows the good fit of predicted and observed NNS for intermediate lesions at a risk index $\geq 5$, and a good fit for diminutive lesions at risk indices between 9 and 20. An NNS of 15, which represents the NNS of the whole cohort to detect advanced neoplasia, was used as a benchmark to distinguish between high-risk (NNS $\leq 15)$ and low-risk (NNS >15) groups. An NNS of $\leq 15$ is reached at a risk index of 5 (NNS 14.8; $95 \%$ CI 14.3 to 15.4) for intermediate, and a risk index of 16 for diminutive, lesions (NNS 14.9; 95\% CI 14.4 to 15.4). The median risk index of all intermediate lesions was 11 (NNS 8.5), and more than $95 \%$ of all intermediate lesions had an index $\geq 5$ (table 6 ), leaving only 1213 (3.42\%) of the 35460 patients with intermediate lesions of the validation set in the low-risk group. In contrast, the median risk index of all diminutive lesions was 9 (NNS 29.4), and less than $5 \%$ of the diminutive lesions had a risk index of $>15$, resulting in a shift of only 1719 (2.59\%) of 66281 patients of the validation set with diminutive lesions into the high-risk group. Exclusion of FOBT + colonoscopies or inclusion of screening colonoscopies only identified similar proportions of high-risk patients in the diminutive and intermediate size groups, respectively (online supplementary table 2 ).

\section{DISCUSSION}

Depending on age, sex and indication for colonoscopy, up to $40 \%$ of colonoscopies reveal findings. Commonly, lesions found on colonoscopy are removed or biopsied for histological assessment. 
Downloaded from http://gut.bmj.com/ on February 10, 2015 - Published by group.bmj.com

Table 2 Prevalence of neoplasia and hyperplastic polyps by size according to the largest lesion found in 1077956 colonoscopies

\begin{tabular}{|c|c|c|c|c|c|}
\hline & $\begin{array}{l}\text { Total } \\
\text { n }(\%)\end{array}$ & $\begin{array}{l}\leq 4 \mathrm{~mm} \\
\mathrm{n}(\%)\end{array}$ & $\begin{array}{l}\text { 5-9 mm } \\
\text { n (\%) }\end{array}$ & $\begin{array}{l}\geq 10 \mathrm{~mm} \\
\mathrm{n}(\%)\end{array}$ & $\begin{array}{l}\text { No size given } \\
\text { n (\%) }\end{array}$ \\
\hline Lesions & 401696 (37.27) & 198954 (18.46) & $106270(9.86)$ & $53490(4.96)$ & 42982 (3.99) \\
\hline Adenoma & 224462 (20.82) & 104455 (9.69) & $75095(6.97)$ & $43138(4.00)$ & $1774(0.17)$ \\
\hline Tubulovillous & $30537(2.83)$ & $5638(0.52)$ & $10800(1.00)$ & $13754(1.28)$ & $345(0.03)$ \\
\hline Tubular & $186075(17.26)$ & $97933(9.09)$ & $62344(5.78)$ & $24604(2.28)$ & $1194(0.11)$ \\
\hline High-grade dysplasia & $5589(0.52)$ & $548(0.05)$ & $1274(0.12)$ & $3569(0.33)$ & $198(0.02)$ \\
\hline Advanced neoplasia & $71831(6.66)$ & $7380(0.69)$ & $13834(1.28)$ & $45290(4.20)$ & $5327(0.49)$ \\
\hline Hyperplastic polyps & $68751(6.38)$ & $46303(4.30)$ & $17197(1.60)$ & $4461(0.41)$ & $790(0.07)$ \\
\hline
\end{tabular}

With the introduction of CT colonography, a general work-up of all patients with subcentimetric lesions by colonoscopy is being disputed. ${ }^{15} 19$ Similar considerations may be applied to capsule endoscopy of the colon in the future. ${ }^{22}$ In our study of 1077956 colonoscopies, which identified a total of 305224 subcentimetric lesions including 21214 subcentimetric lesions with advanced neoplasia, the large sample size allowed us to derive and validate a model to identify independent predictors of advanced neoplasia in diminutive and intermediate lesions. Some of these factors were also predictive of cancer. We successfully aggregated the independent risk factors to build a predictive model that can be applied for stratifying patients with subcentimetric lesions for work-up by colonoscopy after diagnostic imaging of the colon.

The frequency of findings in our cohort is consistent with previous studies. ${ }^{9} 10121323$ In our series, 71831 (6.66\%) colonoscopies performed in symptomatic and asymptomatic patients revealed advanced neoplasia. In other studies, the

Table 3 Prevalence of high grade dysplasia, villous or tubulovillous histology, and cancer within lesions according to size and variable

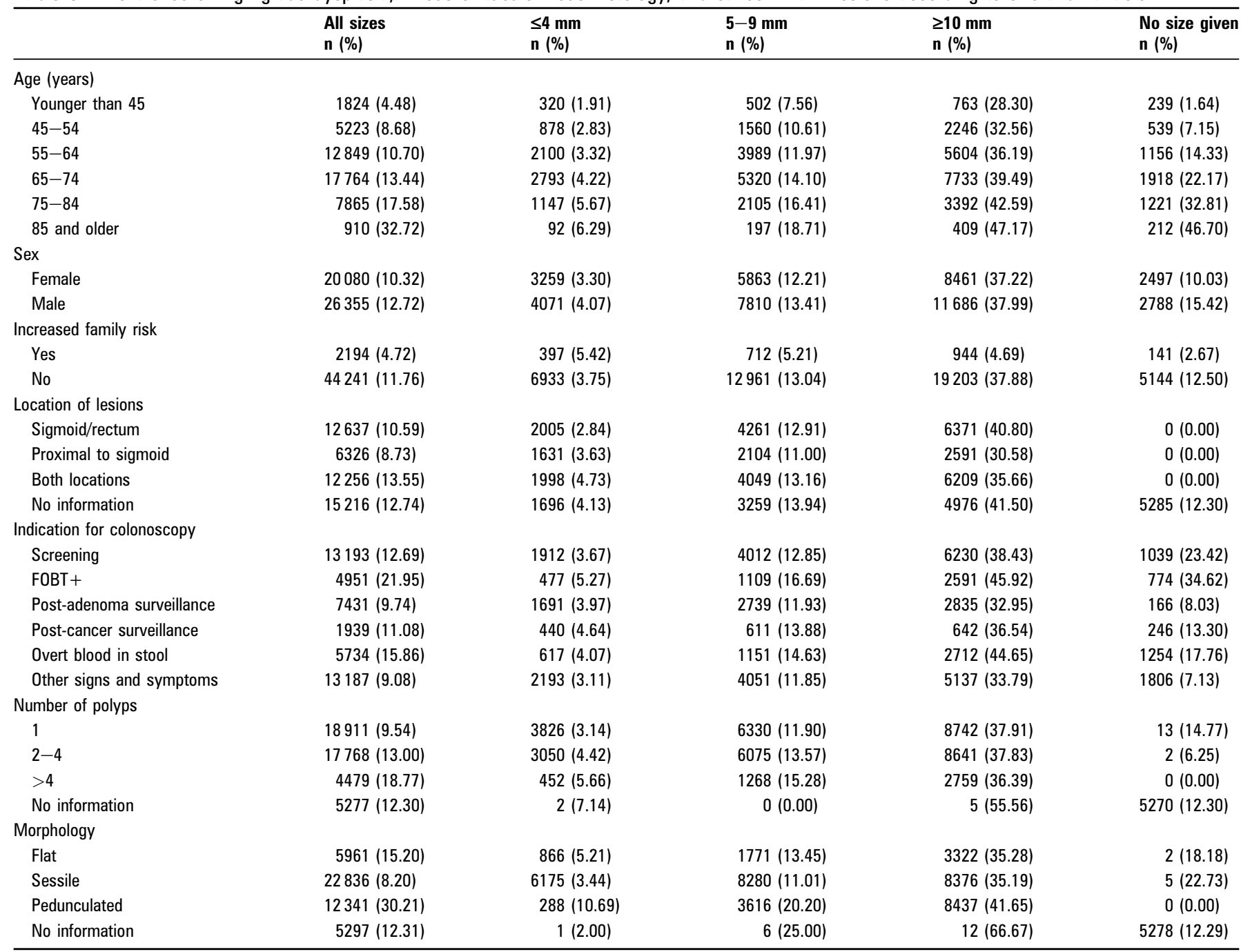

FOBT, faecal occult blood test. 


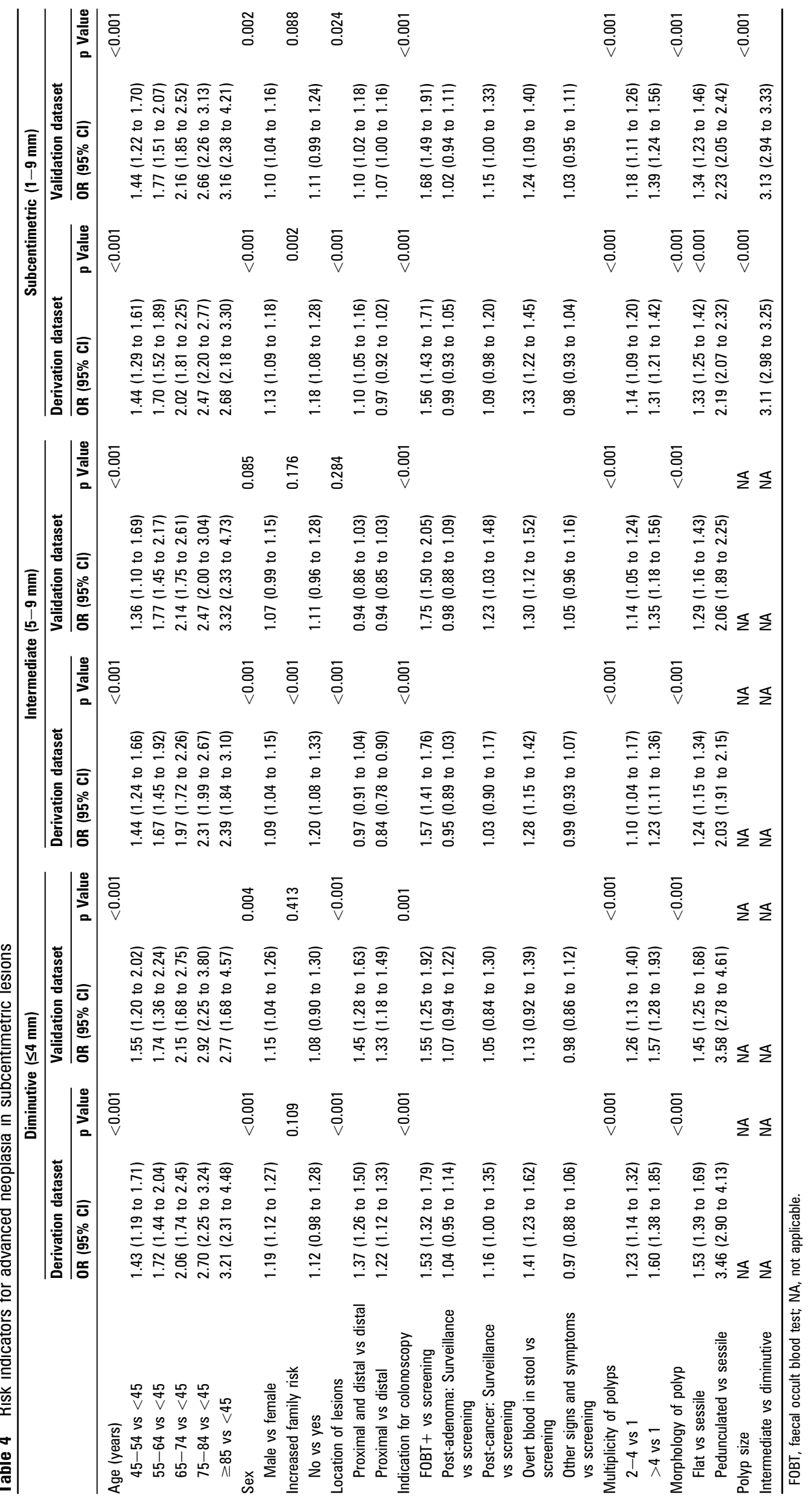


Table 5 Scoring system for the risk index

\begin{tabular}{llc}
\hline Risk factor & Category & Points \\
\hline Age & $<45$ years & 0 \\
& $45-54$ years & 4 \\
& $55-64$ years & 5 \\
& $65-74$ years & 7 \\
& $75-84$ years & 9 \\
& $\geq 85$ years & 10 \\
Sex & Female & 0 \\
Family risk & Male & 1 \\
Blood in stool & No & 2 \\
& Yes & 0 \\
Location of polyps & No & 0 \\
\multirow{3}{*}{ Multiplicity of polyps } & Overt blood & 3 \\
& Occult blood & 4 \\
Morphology of polyp & Proximal or distal only & 0 \\
& Proximal and distal & 1 \\
& 1 & 0 \\
& $2-4$ & 2 \\
& $>4$ & 5 \\
& Sessile & 0 \\
& Flat & 3 \\
\hline
\end{tabular}

reported frequency of advanced neoplasia ranges from $4.8 \%$ in screening series to over $30 \%$ in FOBT positive people. ${ }^{13}{ }^{23} \mathrm{We}$ found that $13 \%$ of all intermediate lesions and $3.7 \%$ of diminutive lesions harboured advanced neoplasia. This is within the range of $5.3 \%$ to $53 \%$ for intermediate and $0.9 \%$ to $17.4 \%$ for diminutive lesions reported by others, ${ }^{13} \quad 23-27$ with lower numbers reported in screening studies and highest frequencies reported in people with occult blood in stool. We identified increasing age, male sex, occult and overt blood, and location, number and morphology of polyps as risk indicators of subcentimetric lesions to contain advanced neoplasia. Only a few studies have previously assessed the risk of advanced neoplasia within lesions. ${ }^{13} 2829$ Lieberman et al ${ }^{13}$ assessed risk factors for polyps in a screening population and also identified

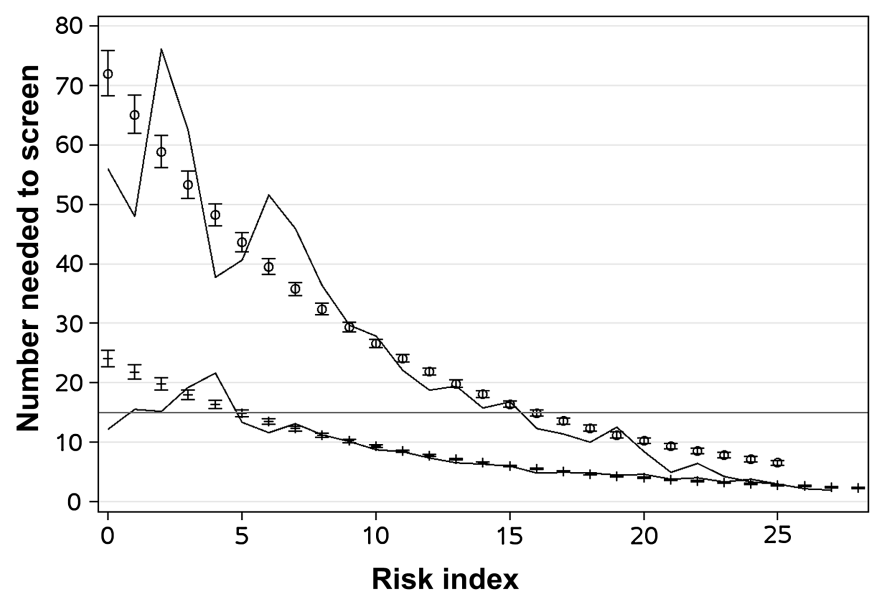

Figure 1 Application of the risk index in the validation sample. The lines depict the number needed to screen (NNS) based on the observed frequencies of advanced neoplasia in patients with diminutive (circles) and intermediate (plus signs) lesions. The data points represent the predictions with $95 \% \mathrm{Cl}$. The bold horizontal line indicates the number needed to screen of 15 of the whole cohort to detect advanced neoplasia, which is used as a benchmark to distinguish between highrisk (NNS $\leq 15$ ) and low-risk (NNS >15) groups.
Table 6 Distribution of risk index counts for diminutive and intermediate lesions

\begin{tabular}{llrllr}
\hline \multirow{2}{*}{ Quantile of patients } & \multicolumn{2}{l}{ Diminutive } & & \multicolumn{2}{l}{ Intermediate } \\
\cline { 2 - 3 } & Risk index & NNS & & Risk index & NNS \\
\hline $100 \%$ & 25 & 6.6 & 28 & 2.3 \\
$99 \%$ & 17 & 13.5 & 22 & 3.4 \\
$95 \%$ & 14 & 18.0 & 19 & 4.3 \\
$90 \%$ & 13 & 19.9 & 17 & 5.1 \\
$75 \%$ & 11 & 24.1 & 14 & 6.5 \\
$50 \%$ (median) & 9 & 29.4 & 11 & 8.5 \\
$25 \%$ & 7 & 35.8 & 9 & 10.2 \\
$10 \%$ & 6 & 39.5 & 7 & 12.3 \\
$5 \%$ & 4 & 48.2 & 6 & 13.5 \\
$1 \%$ & 2 & 65.1 & 2 & 19.8 \\
$0 \%$ & 0 & 71.9 & 0 & 24.0 \\
\hline
\end{tabular}

NNS, number needed to screen.

distal location as a risk factor in intermediate lesions. In contrast with our findings, they failed to identify age and sex as risk factors for advanced neoplasia, which is most likely attributable to the large difference in sample size (1 077956 vs 13992 colonoscopies) between these two studies.

To decide which patients with diminutive and intermediate lesions should receive a work-up by colonoscopy, we adopted a benchmark NNS of 15, which represents the NNS to detect advanced neoplasia in the whole cohort. Any NNS higher than the benchmark would represent a relatively inefficient use of post-test colonoscopy, while the higher the advanced neoplasia rate is, and vice versa, the lower the NNS, the better is the exploitation of colonoscopy. Referral of all patients with any findings on CTC to colonoscopy would strongly conflict with cost-efficiency of CTC. ${ }^{30} 31$ Therefore, risk-adapted work-up of CTC findings may help to cut costs, avoid unnecessary colonoscopies, and increase compliance of patients. Based on this benchmark, what are the clinical implications of our risk index for diminutive lesions? We identified the presence of more than four diminutive polyps, older age, and pedunculated morphology of the polyp as the most important risk factors for diminutive polyps. Application of the risk index and the benchmark NNS of 15 to people with diminutive lesions demonstrates that only a minority of diminutive lesions carries a substantial risk of advanced neoplasia. The small high-risk group of carriers with diminutive lesions that needs to be identified and recommended for immediate work-up by colonoscopy is defined by the presence of the two main risk factors, pedunculated morphology and age $\geq 65$ years, or one of these two in combination with blood in stool and the presence of more than four polyps. Therefore a general non-reporting policy of diminutive lesions ${ }^{15} 19$ does not appear acceptable, as it misses a small but relevant group of high-risk individuals.

Our study also has practical clinical implications for the workup of patients with intermediate lesions. One strategy proposed by the American College of Radiology has suggested colonoscopy for those with three or more polyps 6-9 $\mathrm{mm}$ in size and control by CTC for those with one or two 6-9 $\mathrm{mm}$ lesions. ${ }^{15}$ The index described in this study clearly demonstrates that multiplicity of polyps, morphology and age are important risk factors, which need to be taken into account for decisions about the work-up strategy. Taking into account the median NNS of 8.5 for intermediate lesions and the NNS of 15 of the whole cohort, it becomes obvious that, in contrast with diminutive lesions, the strategy should be to identify people with intermediate lesions who do not require immediate work-up. People 
$\geq 55$ years of age, everybody with a pedunculated polyp, and those $\geq 45$ years of age with one additional risk factor have an NNS to find advanced neoplasia in intermediate lesions that is below the benchmark and therefore require work-up by colonoscopy. This leaves only a small subgroup of people $\leq 45$ years and with a risk index $\leq 4$ where an immediate colonoscopy does not appear necessary. The low-risk group of individuals with intermediate lesions who might be sufficiently followed-up by diagnostic imaging includes young and female adults without evidence of blood in the stool and only one non-pedunculated lesion. Therefore, if not checked for risk factors, all patients with intermediate lesions should rather receive immediate colonoscopy.

Application of the risk index would improve the efficiency of work-up after diagnostic imaging of the colon. It could help to identify individuals with substantial risk of advanced neoplasia, thereby decreasing the number of low-yield colonoscopies and helping to avoid delayed work-up in high-risk groups. Physicians would be given a tool that could help them to give risk-adapted recommendations to their patients rather than, as demonstrated by a recent survey, recommending work-up of all subcentimetric lesions identified on CTC by colonoscopy. ${ }^{32}$ However, a fix cutoff value is difficult to define, and potentially further factors including comorbidities need to be taken into account. Imperiale and colleagues developed a risk index to stratify risk for advanced proximal neoplasia in people undergoing sigmoidoscopy screening. ${ }^{33}$ Points were assigned to the categories, age, sex and most advanced distal finding. Patients deemed to be at intermediate and high risk had an NNS of 24 to detect advanced neoplasia in the proximal colon. Another risk index has been developed to identify low-risk patients who might be good candidates for CTC instead of colonoscopy screening. ${ }^{34}$ Here, points were assigned to the categories sex, age and family history, and the prevalence of advanced neoplasia in the lowand high-risk groups was $3.0 \%$ and $5.7 \%$, corresponding to NNS of 33 and 17.5, respectively. Regula et al studied age, family history and sex as risk factors for advanced neoplasia in a screening population and suggested an NNS of 23 as a threshold for the initiation of screening colonoscopy. ${ }^{10}$ If we used a threshold NNS of 23 or 24 , this would result in the workup of the majority of individuals with diminutive lesions and virtually all with intermediate lesions. Therefore an NNS of 15 might serve as a benchmark to distinguish between a high- and a low-risk group, resulting in an efficient and risk-adapted workup of individuals with subcentimetric findings on diagnostic imaging.

Our findings should be interpreted in the context of the limitations of our study. First, the risk index was indirectly derived from patients undergoing colonoscopy rather from patients undergoing diagnostic imaging. CTC and CCE have lower sensitivities for diminutive and intermediate lesions than colonoscopy, $^{5-9}$ and therefore the number of subcentimetric lesions detected by these techniques would have been lower. However, there is no reason to assume that the relative frequency of advanced neoplasia within lesions would also be different. Second, another limitation is the identification of risk factors in a retrospective study and that the validation process was performed in a subgroup from the same setting of the derivation subgroup. Also, we do not have any information about previous colonoscopies and the time since resection of cancer or adenoma in the surveillance groups. Although there is no reason to assume that this would have any influence on the histology of lesions found, future database documentation should account for this. Only prospective studies can fully overcome the limitations of a retrospective analysis. Still, for the first time, the very large sample size allows the identification of robust risk factors and establishment of a robust, internally validated risk index. Third, it might be argued that the inclusion of non-screening colonoscopies limits our results. Indeed, as screening colonoscopies are not reimbursed under the age of 55 and can therefore not be documented in the database, we lack data about colonoscopies performed for screening in younger adults. Still, we included a total of 258116 screening colonoscopies, the largest series of screening colonoscopies analysed for risk factors in subcentimetric lesions so far. Moreover, our risk index also allows determination of the risk of lesions found in examinations performed for other indications. Fourth, polyp size was determined by the endoscopist and polyps were classified into three predefined size groups. Previous work has suggested that these size estimates may be inaccurate and may result in misclassification of polyps into the wrong size groups. ${ }^{3}$ 35-38 Some studies rely on the measurement of polyp size after removal only ${ }^{24}$ or have determined the size by open biopsy forceps before removal and after polypectomy. ${ }^{25}$ Moreover, one analysis showed that categorisation based on CT colonography measurement into the three size groups differed from prefixation measurement in $43 \%$ of cases. ${ }^{39}$ Sensitivity analysis has been used to estimate the impact of misclassification of polyps on the frequency of advanced histology in size groups. ${ }^{13}$ However, owing to the classification of lesions into size categories by the endoscopists, this analysis is not feasible here. In addition, the categories 'diminutive' and 'intermediate' are defined differently in the literature. Our database classifies diminutive as $\leq 4 \mathrm{~mm}$ and intermediate as $5-9 \mathrm{~mm}$, others have used the size groups $\leq 4 \mathrm{~mm}$ and $5-10 \mathrm{~mm},{ }^{2425}$ and current publications commonly define diminutive polyps as $<6 \mathrm{~mm}$ and intermediate (or small) as $6-9 \mathrm{~mm}^{13} 232627$ The differences in classification and the obvious common misclassification of polyp size is clearly an unsolved and partly unsolvable problem. In clinical practice in particular, the correct classification of polyps may be even more problematic. Drawing rigid cut-offs for size classification is mainly a tribute to practicability, as the risk of a lesion containing advanced adenoma or cancer is continuously increasing with size. ${ }^{24}$ Fifth, there is a relatively small, yet potentially interesting, subgroup for which no lesion size has been reported. These patients exhibit an enormous prevalence of cancer and an unexpectedly low prevalence of hyperplastic polyps. As the majority of colorectal cancers are larger in size and endoscopic size estimation of cancers is often difficult because of circular, semicircular and stenosing growth, the majority of cancers without documentation of size are most likely to occur in the large size group. The reason for the low number of hyperplastic polyps in this subgroup remains unclear, but might be attributable to the fact that, after diagnosis of cancer, other small lesions, especially those exhibiting features of hyperplastic polyps, might not have been endoscopically removed.

In conclusion, our risk index allows the risk-adapted work-up of CTC and CCE findings. On the one hand, this may help to cut costs, avoid unnecessary colonoscopies, and increase compliance of patients. On the other hand, the risk index may also help to avoid the delay in work-up of patients at high risk of advanced neoplasia. Application of the risk index clearly demonstrates that the majority of patients with intermediate lesions have a high risk of advanced neoplasia. Therefore, if not checked for risk factors, all patients with intermediate lesions should rather be followed-up by immediate colonoscopy. A subgroup of patients with diminutive lesions also carries 
a substantial risk of advanced neoplasia. These can be identified and recommended for work-up by colonoscopy. Our risk index should be validated in other cohorts.

Acknowledgements Support from the LMU innovativ Project, Munich Center of Health Sciences, subproject II (evidence-based prevention and modelling of chronic diseases) is gratefully acknowledged.

Contributors Concept and design: FTK, AC, UM, BG. Analysis and interpretation of data: FTK, AC, AG, UM. Acquisition of data: AM. Drafting of the manuscript: FTK, AC. Manuscript review: AG, AM, UM, BG.

\section{Competing interests None.}

Ethics approval Bavarian governmental authority for data protection.

Provenance and peer review Not commissioned; externally peer reviewed.

\section{REFERENCES}

1. Jemal A, Siegel R, Ward E, et al. Cancer statistics, 2009. CA Cancer J Clin 2009;59:225-49.

2. Parkin DM, Bray F, Ferlay J, et al. Global cancer statistics, 2002. CA Cancer J Clin 2005;55:74-108.

3. Levin B, Lieberman DA, McFarland B, et al. Screening and surveillance for the early detection of colorectal cancer and adenomatous polyps, 2008: a joint guideline from the American Cancer Society, the US Multi-Society Task Force on Colorectal Cancer, and the American College of Radiology. Gastroenterology 2008;134:1570-95.

4. Pawa N, Arulampalam T, Norton JD. Screening for colorectal cancer: established and emerging modalities. Nat Rev Gastroenterol Hepatol 2011;8:711-22.

5. Spada C, Hassan C, Munoz-Navas M, et al. Second-generation colon capsule endoscopy compared with colonoscopy. Gastrointest Endosc 2011;74:581-9.e1.

6. Van Gossum A, Munoz-Navas M, Fernandez-Urien I, et al. Capsule endoscopy versus colonoscopy for the detection of polyps and cancer. $N$ Engl J Med 2009;361:264-70.

7. Graser A, Stieber P, Nagel D, et al. Comparison of CT colonography, colonoscopy, sigmoidoscopy and faecal occult blood tests for the detection of advanced adenoma in an average risk population. Gut 2009;58:241-8.

8. Johnson CD, Chen MH, Toledano AY, et al. Accuracy of CT colonography for detection of large adenomas and cancers. N Engl J Med 2008;359:1207-17.

9. Pickhardt PJ, Choi JR, Hwang I, et al. Computed tomographic virtual colonoscopy to screen for colorectal neoplasia in asymptomatic adults. N Engl J Med 2003;349:2191-200

10. Regula J, Rupinski M, Kraszewska E, et al. Colonoscopy in colorectal-cancer screening for detection of advanced neoplasia. N Engl J Med 2006;355:1863-72.

11. Rockey DC, Paulson E, Niedzwiecki D, et al. Analysis of air contrast barium enema, computed tomographic colonography, and colonoscopy: prospective comparison. Lancet 2005;365:305-11.

12. Lieberman DA, Weiss DG, Bond JH, et al. Use of colonoscopy to screen asymptomatic adults for colorectal cancer. Veterans Affairs Cooperative Study Group 380. N Engl J Med 2000;343:162-8.

13. Lieberman D, Moravec M, Holub J, et al. Polyp size and advanced histology in patients undergoing colonoscopy screening: implications for CT colonography. Gastroenterology 2008;135:1100-5.

14. Banerjee S, Van Dam J. CT colonography for colon cancer screening. Gastrointest Endosc 2006:63:121-33.

15. Zalis ME, Barish MA, Choi JR, et al. CT colonography reporting and data system: a consensus proposal. Radiology 2005;236:3-9.

16. Ransohoff DF. CON: Immediate colonoscopy is not necessary in patients who have polyps smaller than $1 \mathrm{~cm}$ on computed tomographic colonography. $A m \mathrm{~J}$ Gastroenterol 2005;100:1905-7; discussion 1907-8.
17. Rex DK. PRO: Patients with polyps smaller than $1 \mathrm{~cm}$ on computed tomographic colonography should be offered colonoscopy and polypectomy. Am J Gastroenterol 2005;100:1903-5; discussion 1907-8.

18. Rex DK, Johnson DA, Anderson JC, et al. American College of Gastroenterology guidelines for colorectal cancer screening 2009 [corrected]. Am J Gastroenterol 2009:104:739-50.

19. Taylor SA, Laghi A, Lefere P, et al. European Society of Gastrointestinal and Abdominal Radiology (ESGAR): consensus statement on CT colonography. Eur Radiol 2007:17:575-9.

20. Rex DK, Kahi CJ, Levin B, et al. Guidelines for colonoscopy surveillance after cance resection: a consensus update by the American Cancer Society and the US MultiSociety Task Force on Colorectal Cancer. Gastroenterology 2006;130:1865-71.

21. Winawer SJ, Zauber AG, Fletcher RH, et al. Guidelines for colonoscopy surveillance after polypectomy: a consensus update by the US Multi-Society Task Force on Colorectal Cancer and the American Cancer Society. Gastroenterology 2006;130:1872-85.

22. Hassan C, Benamouzig R, Spada C, et al. Cost-effectiveness and projected national impact of colorectal cancer screening in France. Endoscopy 2011;43:780-93.

23. Bretagne JF, Manfredi S, Piette C, et al. Yield of high-grade dysplasia based on polyp size detected at colonoscopy: a series of 2295 examinations following a positive fecal occult blood test in a population-based study. Dis Colon Rectum 2010;53:339-45.

24. Butterly LF, Chase MP, Pohl $\mathrm{H}$, et al. Prevalence of clinically important histology in small adenomas. Clin Gastroenterol Hepatol 2006;4:343-8.

25. Gschwantler $\mathbf{M}$, Kriwanek $\mathbf{S}$, Langner $\mathbf{E}$, et al. High-grade dysplasia and invasive carcinoma in colorectal adenomas: a multivariate analysis of the impact of adenoma and patient characteristics. Eur J Gastroenterol Hepatol 2002;14:183-8.

26. Pickhardt PJ, Hain KS, Kim DH, et al. Low rates of cancer or high-grade dysplasia in colorectal polyps collected from computed tomography colonography screening. Clin Gastroenterol Hepatol 2010;8:610-15.

27. Rex DK, Overhiser AJ, Chen SC, et al. Estimation of impact of American College of Radiology recommendations on CT colonography reporting for resection of high-risk adenoma findings. Am J Gastroenterol 2009;104:149-53.

28. Hermanek P, Fruhmorgen P, Guggenmoos-Holzmann I, et al. The malignant potential of colorectal polyps-a new statistical approach. Endoscopy 1983;15:16-20.

29. Nusko G, Mansmann U, Partzsch U, et al. Invasive carcinoma in colorectal adenomas: multivariate analysis of patient and adenoma characteristics. Endoscopy 1997;29:626-31.

30. Lansdorp-Vogelaar I, van Ballegooijen M, Zauber AG, et al. At what costs will screening with CT colonography be competitive? A cost-effectiveness approach. Int $J$ Cancer 2009:124:1161-8.

31. Pickhardt PJ, Hassan C, Laghi A, et al. Cost-effectiveness of colorectal cancer screening with computed tomography colonography: the impact of not reporting diminutive lesions. Cancer 2007;109:2213-21.

32. Shah JP, Hynan LS, Rockey DC. Management of small polyps detected by screening CT colonography: patient and physician preferences. Am J Med 2009;122:687.e1-9.

33. Imperiale TF, Wagner DR, Lin CY, et al. Using risk for advanced proximal colonic neoplasia to tailor endoscopic screening for colorectal cancer. Ann Intern Med 2003;139:959-65.

34. Lin OS, Kozarek RA, Schembre DB, et al. Risk stratification for colon neoplasia: screening strategies using colonoscopy and computerized tomographic colonography. Gastroenterology 2006:131:1011-19.

35. Fennerty MB, Davidson J, Emerson SS, et al. Are endoscopic measurements of colonic polyps reliable? Am J Gastroenterol 1993;88:496-500.

36. Gopalswamy N, Shenoy VN, Choudhry U, et al. Is in vivo measurement of size of polyps during colonoscopy accurate? Gastrointest Endosc 1997;46:497-502

37. Morales TG, Sampliner RE, Garewal HS, et al. The difference in colon polyp size before and after removal. Gastrointest Endosc 1996;43:25-8.

38. Schoen RE, Gerber LD, Margulies C. The pathologic measurement of polyp size is preferable to the endoscopic estimate. Gastrointest Endosc 1997:46:492-6.

39. Gupta S, Durkalski V, Cotton $P$, et al. Variation of agreement in polyp size measurement between computed tomographic colonography and pathology assessment: clinical implications. Clin Gastroenterol Hepatol 2008;6:220-7. 


\section{GUT}

Risk factors for advanced neoplasia within subcentimetric polyps: implications for diagnostic imaging

Frank Thomas Kolligs, Alexander Crispin, Anno Graser, Axel Munte, Ulrich Mansmann and Burkhard Göke

Gut 2013 62: 863-870 originally published online April 23, 2012

doi: 10.1136/gutjnl-2011-300111

Updated information and services can be found at:

http://gut.bmj.com/content/62/6/863

These include:

Supplementary Supplementary material can be found at:

Material http://gut.bmj.com/content/suppl/2012/04/23/gutjnl-2011-300111.DC1. html

References This article cites 39 articles, 1 of which you can access for free at: http://gut.bmj.com/content/62/6/863\#BIBL

Email alerting Receive free email alerts when new articles cite this article. Sign up in the service box at the top right corner of the online article.

Topic Articles on similar topics can be found in the following collections

Collections

Colon cancer (1464)

Endoscopy (971)

\section{Notes}

To request permissions go to:

http://group.bmj.com/group/rights-licensing/permissions

To order reprints go to:

http://journals.bmj.com/cgi/reprintform

To subscribe to BMJ go to:

http://group.bmj.com/subscribe/ 